\title{
Are they in or out? Commentary on... The College and the independent sector ${ }^{\dagger}$
}

Until recently the majority of mental health service providers in the UK were National Health Service (NHS) trusts. Now there are roughly equal numbers of providers in the NHS and the independent sector, and the majority of the latter are funded almost entirely by the NHS. They are part of what the previous Secretary of State for Health in England and Wales started to call the 'NHS family'. Most of these independent providers are quite small but many are growing, and the number of specialists working in such enterprises is therefore also increasing.

Sugarman \& Nimmagadda (2007, this issue) rightly, in my view, challenge the College and thus its membership to examine our prejudices about and ignorance of practice outside the traditional NHS, a criticism that has long been levied by colleagues working in the Republic of Ireland, where there is no NHS.

I have asked several colleagues about their attitudes and feelings about the growth of the independent sector. Many NHS consultants I have spoken to view the independent sector negatively, bearing out Sugarman \& Nimmagadda's concerns. They express frustrations about the success of private entrepreneurship in filling a market gap that NHS consultants have long been aware of, but unable to meet because of planning blight and commissioning failings in the NHS. They feel cheated when trainees expensively trained and supervised in the NHS are headhunted for well-paid posts in a sector that doesn't contribute to training. They quite rightly object if private units fail to pay sufficient attention to rehabilitation, and feel impotent to affect the placement of their own patients so far from home that home ties are too easily weakened and lost. These are real concerns but things are changing so rapidly that we can either keep our heads in the sand or face up to the need for collaboration. After all the College's charter doesn't restrict us to working with the NHS. The College has nearly 13000 Members and Fellows worldwide; probably two-thirds work primarily in the NHS, but not necessarily exclusively. We should be concerned with clinical standards in all mental health services. Also the revalidation agenda in the UK will look to the College to provide evidence for recertification of all psychiatrists, not just NHS psychiatrists.

Look at continuing professional development (CPD) peer groups for example. My own peer group includes a 'retired' member who continues to work in single-handed private practice, and our group's discussions are enhanced by his insights and experience from outside the NHS. However, it would have been difficult for him to form a peer group without a welcome from willing NHS colleagues.

The new consultants' contracts in the UK jurisdictions and the lack of any certainty about the availability, shape and duration of specialist posts in the future, will lead many senior trainees to inform themselves about opportunities for remunerable employment outside the NHS. Developing opportunities for choosing a training placement in the independent sector will enable this.

Do political views about the rights and wrongs of current NHS commissioning decisions dominate the agenda of the College's Central Executive Committee? How far do our concerns about standards of psychiatric practice relate to all sectors in all of our jurisdictions? I consider that there has been a change. However, change in a democratic system often waits for members to provoke it. Now that Sugarman \& Nimmagadda are both members of the Central Executive Committee they will be able to affect the agenda directly. There will remain issues that are of importance only to NHS employees, such as Advisory Committee on Clinical Excellence Awards nominations, but both clinical quality improvement and training standards apply across the board. It is for them to raise issues exclusive to their sector and for others to respond in an open, non judgemental way. Most of the agenda will continue to apply to psychiatrists wherever we work.

\section{Reference}

SUGARMAN, P. \& NIMMAGADDA, independent sector. Psychiatric S. R. (2007) The College and the Bulletin, 31,404-406.

Sheila Hollins President, Royal College of Psychiatrists, 17 Belgrave Square, London SW1 8PG, email: shollins@rcpsych.ac.uk opinion \& debate 